\title{
SHORT-TERM SPECTRAL ANALYSIS OF HEART RATE VARIABILITY DURING SUPINE-STANDING-SUPINE TEST IN PATIENTS WITH PAROXYSMAL ATRIAL FIBRILLATION
}

\author{
Jan Galuszkaa , Jaroslav Opavskýb, Jan Lukl ${ }^{\mathrm{a}}$, Pavel Stejskal ${ }^{\mathrm{c}}$, Jana Zapletalovád, Jiří Salinger ${ }^{\mathrm{e}}$ \\ ${ }^{a} I^{\text {st }}$ Department of Internal Medicine, Faculty of Medicine \\ ${ }^{b}$ Department of Physiotherapy and Pain Management, Faculty of Physical Culture \\ c Department of Functional Anthropology and Physiology, Faculty of Physical Culture \\ ¿ Department of Biometrics, Faculty of Medicine \\ e Department of Biomechanics and Technical Cybernetics, Faculty of Physical Culture, Palacký University Olomouc, Czech \\ Republic, e-mail: jan.galuszka@fnol.cz
}

Received: April 7, 2004; Accepted: June 5, 2004

Key words: Atrial fibrillation/Supine-standing-supine test/Heart rate variability/Spectral analysis/Vagal activity/Sympathetic activity

The aim of the study was to assess the sympathovagal balance in group of 27 patients without significant structural heart disease after an attack of atrial fibrillation. The investigation was performed using spectral analysis of heart rate variability during examination under conditions of different orthostatic loads in single phases, called the supine-standing-supine test. The findings were compared with a group of healthy persons. These revealed a significantly decreased total spectral power (430.7 vs $1558.0 \mathrm{~ms}^{2}$ supine 1; 477.6 vs $1042,5 \mathrm{~ms}^{2}$ standing; $567.5 \mathrm{vs} 1948.5 \mathrm{~ms}^{2}$ supine2), and spectral power of the high frequency spectral component (140.8 vs $619.3 \mathrm{~ms}^{2}$ supine 1; $96.2 \mathrm{vs} 203.3 \mathrm{~ms}^{2}$ standing; 186.3 vs $739.4 \mathrm{~ms}^{2}$ supine2) in the studied group of patients in comparison with the control group.

\section{INTRODUCTION}

Atrial fibrillation (AF) is arrhythmia of increasing importance in ageing populations. ${ }^{1,2}$ It has been characterized as a syndrome with complicated aetiopathogenetic mechanism involving the nervous system. ${ }^{3}$ The autonomic nervous system (ANS), in particular, is the homeostatic body system with influence on arrhythmogenesis as a modulating or even triggering factor. ${ }^{4,5,6}$ Spectral analysis (SA) of heart rate variability (HRV) is a promising noninvasive method of ANS evaluation which offers both qualitative and quantitative assessment of sympatho-vagal interactions. ${ }^{7}$ This method enables us in short-term recordings to distinguish three main components in the frequency domain: very low frequency VLF $(10-50 \mathrm{mHz})$, low frequency LF $(50-150 \mathrm{mHz})$ and high frequency HF $(150-400 \mathrm{mHz})^{7}$ The majority of hitherto studies focused on ANS evaluation in paroxysmal AF have been based on long-term ECG recordings. In these tachograms, analysed were either total HRV during the whole period of the preceding sinus rhythm before $\mathrm{AF}$ attack ${ }^{8}$ or short-term (20 minutes) time segments before or $^{9}$ after $^{10}$ attack. We examined the SA of short-term HRV during the supinestanding-supine test ${ }^{11}$ in patients after $\mathrm{AF}$ attack.

\section{MATERIAL AND METHODS}

Inclusion criteria: $\mathrm{ECG}$ documented $\mathrm{AF}$ with a duration of less than 48 hours, normal left atrium diameter on echocardiography examination,,$^{12}$ age under 70 years.

Exclusion criteria: significant structural heart disease, acute coronary syndrome, valvular heart disease, other acute or severe diseases.

After selection of patients according to the above criteria, 27 persons ( 18 men, 9 women), mean age 54.2 years (range 35.5-69), were referred for examination. Underlying diseases in the study group comprised hypertension (44\%), structural heart disease (30\%), diabetes mellitus (11\%), combination of the above illnesses ( $26 \%$ ), and lone AF (37\%). All were in stable NYHA class I (59\%) or II (41\%) with an average left atrium diameter $38 \mathrm{~mm}$, body mass index 26.4, TSH $2.54 \mathrm{mIU} / 1$.

All the patients were examined under standard conditions between 8 and 11 a.m. at room temperature of 22 to 25 degrees Celsius after elimination of cigarettes, alcohol and coffee consumption at least 12 hours beforehand. Medication potentially influencing HRV was stopped (52\%) or administered for the last time the day before examination (Propafenon $33 \%$, angiotensin converting enzyme inhibitors $29 \%$, Digoxin $11 \%$, betablockers $11 \%)$. The patients remained in each position for 5 minutes during supine-standing-supine test to record at least 300 R-R intervals . The examinations were performed by means of the telemetric diagnostic system VARIA PULSE 
TF $3^{13}$ and VARIA CARDIO TF4. ${ }^{14}$ The spectral analysis of HRV using fast Fourier transformation partially modified according to Yamamoto (coarse-graining spectral analysis) was used for data processing. The following parameters were used for evaluation: total spectral power (TOT. PWR), spectral power of VLF, LF, HF components, LF/HF ratio which denominated as a marker of sympatho-vagal balance, ${ }^{15}$ coefficient of component variance (CCV) to eliminate differences in mean R-R level and their impact on the amplitude of oscillations. ${ }^{16}$ The values of LF and HF were expressed in absolute $\left(\mathrm{ms}^{2}\right)$ and normalized units. ${ }^{7}$

The values of parameters obtained in the patient group were compared with the results of a corresponding (age and gender matched) heatlthy subject group (27 persons, mean age 51.1 years, range $35.1-68.8) .{ }^{17,18}$

\section{RESULTS}

The results of the supine-standing-supine test are shown both in tabular and graphic formats, including 3-dimensional graphs.

The data are summarized in Tables 1-5. The mean values and standard deviation (SD) of the total spectral power and spectral powers of single frequency components in supine-standing-supine positions are shown in Table 1.

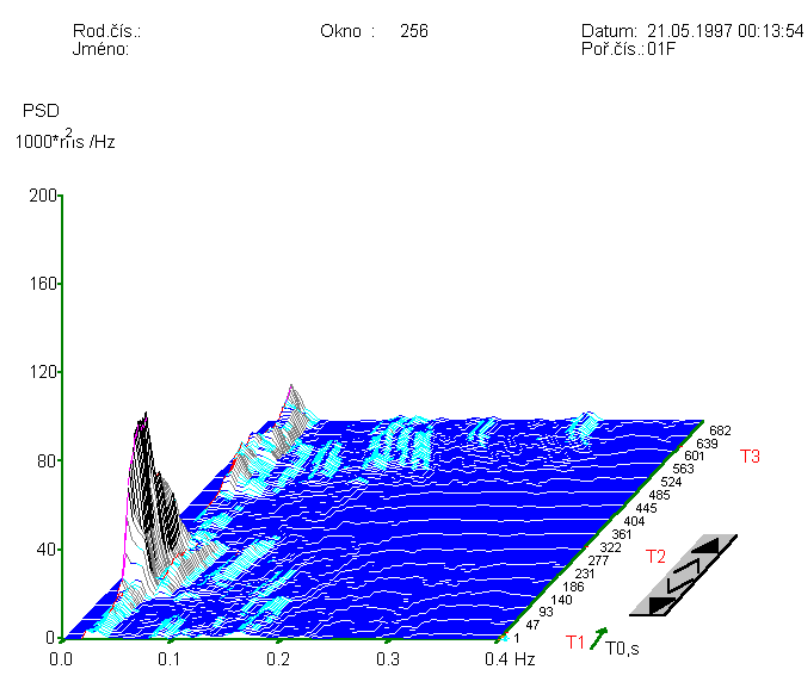

Fig. 1. (patient)

The results of spectral analysis of heart rate variability during the supine-standing-supine test in 3D graph show abnormal finding of striking attenuation of spectral component with the involvement of vagal and sympathetic component in a man 36 years old with a history of atrial fibrillation.

Legend: PSD - power spectral density, T1 - time of initial supine position, T2 - time of standing position, T3 - time of final supine position.
The mean values of $\mathrm{CCV}$ in the patient group $(\mathrm{P})$ and in the healthy controls $(C)$ in the course of the supinestanding-supine test are shown in Table 2.

The average values of total spectral power and spectral power and density of LF and HF components compared between the patient group (P) and the healthy controls (C) during the clinostatic phase of the supine-standingsupine test expressed as differences in values of standing phase minus supine 2 phase are shown in Table 3.

$\mathrm{LF} / \mathrm{HF}$ spectral components ratios during the supine-standing-supine test in the patient group $(\mathrm{P})$ and the healthy controls $(C)$ are shown in Table 4.

Comparison of changes of LF and HF spectral components during the supine-standing-supine test between the patient group (P) and the healthy controls (C) was expressed in normalized units (Table 5).

The most important differences between mean values of each LF and HF components in normalized unit were found having compared supine 1 versus standing position, and standing versus supine 2 position. These differences have confirmed the dynamics of the autonomic nervous system responses within the scope of this test when the values of the significance of the changes equalled 0.006 and/or 0.001 in the patient group and 0.0003 for the healthy controls.

These differences demonstrate great sensitivity of the supine-standing-supine test for evaluation of autonomic regulation of heart rate.

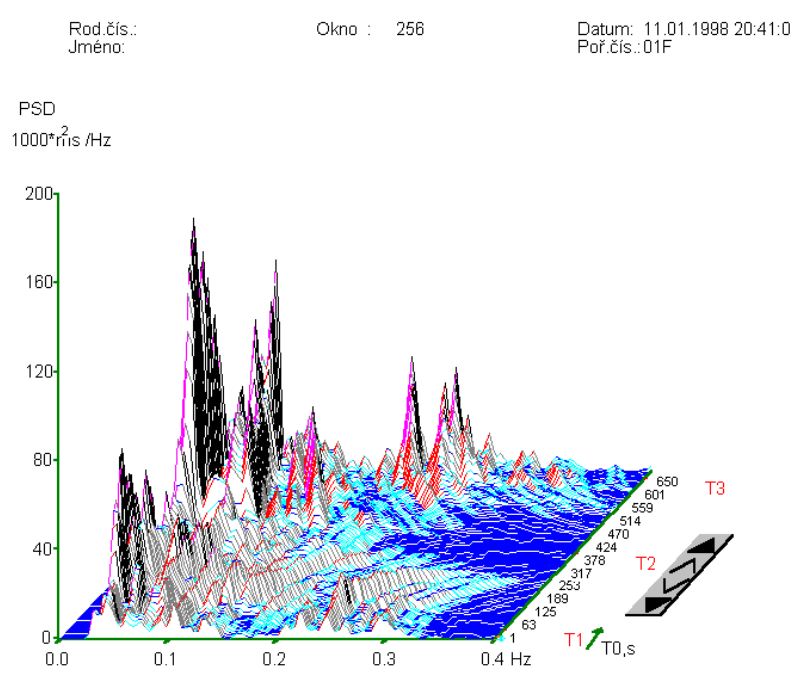

Fig. 2. (control)

The results of spectral analysis of heart rate variability during the supine-standing-supine test in 3D graph show normal finding with good expression of spectral component dynamics in a healthy, 42-years-old man.

Legend: PSD - power spectral density, T1- time of initial supine position, T2 - time of standing position, T3 - time of final supine position. 
Table 1. Spectral analysis of heart rate variability during the supine-standing-supine test -comparison of the mean spectral power values between the patient group (P) and healthy controls (C) expressed in spectral parameters of single frequency components and total power.

\begin{tabular}{|l|rr|rr|c|}
\hline \multicolumn{1}{|c|}{ Spectral power $\left(\mathbf{m s}^{2}\right)$} & \multicolumn{2}{|c|}{ Patients } & \multicolumn{2}{c|}{ Control } & \multicolumn{1}{c|}{ p } \\
\hline VLF supine1 $(S D)$ & 101.5 & $(69.7)$ & 314.3 & $(503.3)$ & $\mathbf{0 . 0 0 1}$ \\
\hline VLF standing $(S D)$ & 112.5 & $(105.1)$ & 223.9 & $(248.4)$ & $\mathbf{0 . 0 1 6}$ \\
\hline VLF supine2 $(S D)$ & 162.4 & $(202.9)$ & 419.5 & $(353.0)$ & $\mathbf{0 . 0 0 1}$ \\
\hline LF supine1 $(S D)$ & 188.5 & $(212.4)$ & 624.4 & $(599.8)$ & $\mathbf{0 . 0 0 0 3}$ \\
\hline LF standing $(S D)$ & 268.8 & $(494.1)$ & 615.3 & $(601.4)$ & $\mathbf{0 . 0 0 0 3}$ \\
\hline LF supine 2 $(S D)$ & 218.8 & $(256.5)$ & 789.6 & $(706.3)$ & $\mathbf{0 . 0 0 0 0 1}$ \\
\hline HF supine1 $(S D)$ & 140.8 & $(122.4)$ & 619.3 & $(612.5)$ & $\mathbf{0 . 0 0 0 1}$ \\
\hline HF standing $(S D)$ & 96.2 & $(154.4)$ & 203.3 & $(214.3)$ & $\mathbf{0 . 0 0 6}$ \\
\hline HF supine2 $(S D)$ & 186.3 & $(175.4)$ & 739.4 & $(744.3)$ & $\mathbf{0 . 0 0 0 0 3}$ \\
\hline TOTAL supine1 $(S D)$ & 430.7 & $(336.1)$ & 1558.0 & $(1218.2)$ & $\mathbf{0 . 0 0 0 0 2}$ \\
\hline TOTAL standing $(S D)$ & 477.6 & $(645.7)$ & 1042.5 & $(880.6)$ & $\mathbf{0 . 0 0 0 3}$ \\
\hline TOTAL supine2 $(S D)$ & 567.5 & $(466.7)$ & 1948.5 & $(1410.8)$ & $\mathbf{0 . 0 0 0 0 1}$ \\
\hline
\end{tabular}

Legend: Mann-Whitney U test, Patients $\mathrm{N}=27$, Controls $\mathrm{N}=27$. SD standard deviation. The most marked differences were in the HF component. The differences between the groups under study were more pronounced for all three spectral components in supine position, and sometimes they were even fourhold.

Table 2. Spectral analysis of heart rate variability during the supine-standing-supine test - comparison of coefficients of component variance mean values between the patient group $(\mathrm{P})$ and the healthy controls $(\mathrm{C})$ expressed in \%.

\begin{tabular}{|l|l|l|l|}
\hline \multicolumn{1}{|c|}{ CCV } & $\mathrm{P}$ & $\mathrm{C}$ & $\mathrm{p}$ \\
\hline VLF supine 1 & 0.977 & 1.595 & $\mathbf{0 . 0 0 1}$ \\
\hline VLF standing & 1.209 & 1.675 & $\mathbf{0 . 0 1 3}$ \\
\hline VLF supine 2 & 1.177 & 1.87 & $\mathbf{0 . 0 0 2}$ \\
\hline LF supine 1 & 1.264 & 2.334 & $\mathbf{0 . 0 0 1}$ \\
\hline LFstanding & 1.611 & 2.835 & $\mathbf{0 . 0 0 1}$ \\
\hline LF supine 2 & 1.35 & 2.565 & $\mathbf{0 . 0 0 0 1}$ \\
\hline HF supine 1 & 1.136 & 2.267 & $\mathbf{0 . 0 0 0 1}$ \\
\hline HF standing & 0.978 & 1.588 & $\mathbf{0 . 0 0 7}$ \\
\hline HF supine 2 & 1.309 & 2.39 & $\mathbf{0 . 0 0 0 1}$ \\
\hline
\end{tabular}

Legend: Mann-Whitney U test, (P) Patients $\mathrm{N}=27,(\mathrm{C})$ Controls $\mathrm{N}=27$. CCV coefficients of component variance. There were significant differences between both the groups $(\mathrm{P}$ and $\mathrm{C}$ ) in powers of all the three spectral components after calculations of heart rate influences expressed in CCV.

Table 3. Spectral analysis of heart rate variability during the clinostatic phase of the supine-standing-supine test - mean value differences in spectral power and spectral density of LF, HF components (standing value minus supine 2 value) in the patient group $(\mathrm{P})$ and the healthy controls $(\mathrm{C})$.

\begin{tabular}{|l|r|r|r|r|c|}
\hline Difference standing-supine 2 & $\mathrm{P}$ & $\mathrm{p}$ & $\mathrm{C}$ & $\mathrm{p}$ & $\mathrm{P}: \mathrm{C} \mathrm{p}$ \\
\hline PWR.LF & 50.1 & 0.885 & -174.3 & 0.220 & 0.223 \\
\hline PWR.HF & -90.1 & $\mathbf{0 . 0 0 1}$ & -536.1 & $\mathbf{0 . 0 0 0 0 1}$ & $\mathbf{0 . 0 0 1}$ \\
\hline PSD.LF & 6313.5 & 0.773 & -8521.8 & 0.337 & 0.431 \\
\hline PSD.HF & -2832.4 & $\mathbf{0 . 0 0 1}$ & -10313.8 & $\mathbf{0 . 0 0 0 2}$ & $\mathbf{0 . 0 3 7}$ \\
\hline TOT.PWR & -90.0 & $\mathbf{0 . 0 4 9}$ & -906.00 & $\mathbf{0 . 0 0 3}$ & $\mathbf{0 . 0 4 0}$ \\
\hline
\end{tabular}

Legend: Difference P, C Wilcoxon test, diference P:C Mann-Whitney U test, (P) Patients N=27, (C) Controls N=27. PWR power $\left(\mathrm{ms}^{2}\right)$, PSD power spectral density $\left(\mathrm{ms}^{2} / \mathrm{Hz}\right)$. There was a significant increase in PWR.HF and PSD.HF components in the clinostase (negative value of differences) in both the groups under study, but much more pronounced in the control group. This change reflecting vagal loading is also responsible for the significant increase in total spectral power in both groups. 
Table 4. Spectral analysis of heart rate variability during the supine-standing-supine test; LF/HF ratio during the supine-standing-supine test in the patient group $(\mathrm{P})$ and in the healthy controls (C) expressed as mean values and standard deviations.

\begin{tabular}{|l|c|c|c|}
\hline \multicolumn{1}{|c|}{ Ratio } & Patients & Controls & $\mathrm{p}$ \\
\hline LF/HF supine1 (SD) & $1.6(1.4)$ & $1.5(1.1)$ & 0.71 \\
\hline LF/HF standing (SD) & $5.4(6.9)$ & $5.5(5.0)$ & 0.28 \\
\hline LF/HF supine2 (SD) & $1.5(1.5)$ & $1.5(1.0)$ & 0.382 \\
\hline
\end{tabular}

Legend: Mann-Whitney U test, (P) Patients N=27, (C) Controls $\mathrm{N}=27$. No significant differences were found between patient and control groups. Changes in LF/HF balance were similar in both groups for single phases of the supine-standing-supine test.

Table 5. Spectral analysis of heart rate variability during the supine-standing-supine test - comparison of mean values of spectral components LF, HF between the patient group (P) and the healthy controls $(\mathrm{C})$ expressed in nu (normalized units).

\begin{tabular}{|c|c|c|c|}
\hline nu & Patients & Controls & $\mathrm{p}$ \\
\hline LF supine 1 $(S D)$ & $0.51(0.21)$ & $0.53(0.20)$ & 0.710 \\
\hline LF standing $(S D)$ & $0.66(0.26)$ & $0.73(0.20)$ & 0.710 \\
\hline LF supine 2 $(S D)$ & $0.48(0.22)$ & $0.54(0.17)$ & 0.272 \\
\hline HF supine 1 $(S D)$ & $0.49(0.21)$ & $0.47(0.20)$ & 0.272 \\
\hline HF standing $(S D)$ & $0.34(0.26)$ & $0.27(0.20)$ & 0.382 \\
\hline HF supine 2 $(S D)$ & $0.52(0.22)$ & $0.46(0.17)$ & 0.38 \\
\hline
\end{tabular}

Legend: Normalized units are used to express the relationship between LF and HF components differently from the $\mathrm{LF} / \mathrm{HF}$ ratio. A normalized unit is a relative value for each power component in propotion to the total minus the VLF component. ${ }^{7}$ These results show a similar sympathovagal balance between both the study groups during testing.

\section{DISCUSSION}

Supine-standing-supine test measures a dynamic loading of the autonomic nervous system in the form of a sequentional increase in the sympathetic activity and concomitant decrease in the vagal activity in the standing position, and also decrease in the sympathetic and increase in the vagal activity in the supine position after lying back.

We found significantly lower total spectral power as well as power of single spectral components in the patient group. There were no significant diferences between the groups in sympathovagal balance represented by the LF/ $\mathrm{HF}$ ratio as a result of proportional attenuation of both the parameters. The patients had similar response to the studied test but their regulatory mechanisms oscillated in a smaller range.

It was not possible to withdraw medication before examination in all patients, but according to the references $^{7,19,20}$ we might to suppose their vagomimetic and/ or neutral influence on the automonic nervous system. Therefore, it was difficult to explain the total low power and especially low power of the HF component by the above medication.

Evaluation of ratio $\mathrm{LF} / \mathrm{HF}>2$, which Lombardi ${ }^{10}$ termed a predictor of early recurrence of AF revealed this value as $29 \%$. This percentage would probably be higher without the mentioned medication, in particular betablockers.

The supine-standing-supine test offers an easy way for evaluating the integrity of the autonomic heart regulations. Our results confirm significant differences between both studied groups. The applied test was effective to reliably differentiate between the patient group and that of healthy individuals. The changes in the autonomic nervous system reactivity may be considered as a factor contributing to the origin of arrhythmias. One of the inclusion criteria for the patient group was a normal diameter of the left atrium, and hence it might be supposed that there was no atrial anatomic remodellation. More studies dealing with $\mathrm{AF}$ and focused on individual evaluation would be needed in the future because of the complexity of AF etiopathogenesis. The supine standing-supine test seems to be a suitable complement to standard examination of patients with AF.

\section{ACKNOWLEDGEMENTS}

The authors wish to thank Ms. Jarmila Potomkova and Mr. Alec Oulton for editorial work, and to Mr. Leo Rec for his graphic aid.

\section{REFERENCES}

1. Benjamin EJ, Wolf PA, D’Agostino RB, Silbershatz H, Kannel WB, Levy D1. (1998) Impact of atrial fibrillation on the risk of death: The Framingham Heart Study. Circulation 98, 946-952.

2. Domanski MJ. (1995) The epidemiology of atrial fibrillation. Coron Artery Dis 6, 95-96.

3. Shah DC, Haïssaguerre M, Jaïs P. (2001) Toward a mechanismbased understanding of atrial fibrillation. J. Cardiovasc Electrophysiol 12, 600-601.

4. Bigger JT, Günter B, Brown AM, Camm AJ, Carmeliet E, Fozzard HA, Hoffman BF, Janse MJ, Lazzara R, Mugelli A, Myerburg RJ, Roden DM, Rosen MR, Schwartz PJ, Strauss HC, Woosley RL, Zaza A, Campbell RWF, Waldo AL (1991) The Sicilian Gambit. A New Approach to the Classification of Antiarrhythmic Drugs Based on Their Actions on Arrhythmogenic Mechanisms. Task Force of the Working Group on Arrhythmias of the European Society of Cardiology. Circulation 84, No 4,1831-1851.

5. Fuster V, Rydén LE, Asinger RW, et al. (2001) ACC/AHA/ESC guidelines for the management of patients with atrial fibrillation: a report of the American College of Cardiology / American Heart Association Task Force on Practice Guidelines and the European Society of Cardiology Committee for Practice Guidelines and Policy Conferences (Committee to Develop Guidelines for the 
Management of Patients With Atrial Fibrillation). Eur Heart J 2, $1852-1923$.

6. Lévy MN. (1998) Autonomic nervous system in atrial flutter and fibrillation. In: Saoudi A, Schoels W, El-Sherif N (eds.). Atrial Flutter and Fibrillation. From Basic to Clinical, Armonk, NY, Futura Publishing Company, 69-85.

7. Task Force of the European Society of Cardiology and the North American Society of Pacing and Electrophysiology. Heart Rate Variability. Standards of Measurement, Physiological Interpretation, and Clinical Use. (1996) Circulation 93, 5,1043-65.

8. Frost L, Mølgaard H, Christiansen EH, Jacobsen CJ, Allermand H, Thomsen PEB. (1995) Low vagal tone and supraventricular ectopic activity predict atrial fibrillation and flutter after coronary artery bypass grafting. Eur Heart J 16, 825-831.

9. Herweg B, Dalal P, Nagy B, Schweitzer P. (1998) Power spectral analysis of heart period variability of preceding sinus rhythm before initiation of paroxysmal atrial fibrillation. Am $\mathbf{J}$ Cardiol 82, 869-874.

10. Lombardi F, Colombo A, Basilico B, Ravaglia R, Garbin M, Vergani D, Battezzati PM, Fiorentini C. (2001) Heart rate variability and early recurrence of atrial fibrillation after electrical cardioversion. J Am Coll Cardiol 37, 157-162.

11. Opavský J, Salinger J. (2002) Supine-standing-supine test in diabetic autonomic neuropathy diagnostics: a contribution to the assessment of vagal activity with the use of short-term spectral analysis of heart rate variability (abstract). Eur J Neurol. 9 (suppl 2), 144.

12. Gregor P, Widimský P, Niederle P. (1984) Echokardiografie, 2. přepracované vydání, Avicenum, zdravotnické nakladatelství, Praha 326.

13. Salinger J, Vychodil R, Novotný J, Pumprla J, Opavský J, Stejskal P, Vaverka F, Bula J. (1995) Telemetric, computer-aided system for non-invasive examination of heart rate variability, type Varia Pulse TF3. In: Murray, A., Arzbaecher, R. (eds.) Computers in Cardiology. Los Alamitos: The Institute of Electrical and Electronics Engineers, Computer Society Press, 437-440.

14. Salinger J, Pumprla J, Vychodil R, Stejskal P, Opavský J, Novotný J, Bula J. (1999) Microcomputer System for Telemetric Assessment of Short Term Heart Rate Variability in Time and Frequency Domain, Type VariaCardio TF4. In: Murray, A., Swiriyn, S., (eds) Computers in Cardiology, Los Alamitos: The Institute of Electrical and Electronics Engineers, Computer Society Press, 599-602.

15. Pagani M, Lombardi F, Guzzeti S, Rimoldi O, Furlan R, Pizzinelli P, Sandrone G, Malfatto G, Dell'Orto S, Piccaluga E. (1986) Power spectral analysis of heart rate and arterial pressure variabilities as a marker of sympathovagal interactions in man and conscious dog. Circ Res 59,178-193.

16. Hayano J, Sakakibara Y, Yamada A, Yamada M, Mukai S, Fujinami T, Yokoyama K, Watanabe Y, Takata K. (1991) Accuracy of assessment of cardiac vagal tone by heart rate variability in normal subject. Am J Cardiol 67, 199-204.

17. Šlachta R, Stejskal P, Elfmark M, Salinger J, Jurča R., Kalina M, Řehořová I. (2002) Age and heart rate variability. Acta Uniy Palacki Olomuc Gymnica 32 (1), 59-67.

18. S Slachta R. (1999) Sledování závislosti hodnoty ukazatelů spektrální analýzy variability srdeční frekvence na věku vyšetřovaných osob. Disertační práce. Fakulta tělesné kultury Palackého univerzity, 0lomouc.

19. Lü Fei. (1995) Effects of pharmacological interventions on heart rate variability. In: Malik, M., Camm, A.J. (eds).: Heart Rate Variability, Armnonk, New York, Futura Publishing Comnpany, Inc, 275-285

20. Watanabe AM. (1985) Digitalis and autonomic nervous system. J Am Coll Cardiol 5, 35A-41A. 